\title{
Legitimation of knowers for access in science
}

\section{Karen Ellery}

CHERTL, Rhodes University

k.ellery@ru.ac.za

http://orcid.org/0000-0003-3974-4974

(Received 26 October 2017; accepted 01 May 2018)

\section{Abstract}

Based on poor performance of students in the higher education science context, this paper questions the current focus on content knowledge and, in so doing, examines the role student knowers play in enabling epistemological access. Using Legitimation Code Theory, and drawing on data from interviews, course documents, observations, and critical reflections, the social relations of a science foundation course in the South African context are examined empirically to reveal the valuing of two kinds of knowers-learning-context knowers (or science learners) and production-context knowers (or scientists). Since being both kinds of knowers is necessary for access to powerful science knowledge, and home and educational contexts of certain groups of students are better in terms of enabling science knowers and learners than others, it is argued from a social justice perspective that science (and other) curricula account for knower attributes in enabling access for success for all students.

Keywords: science access; Legitimation Code Theory; knowers

\section{Introduction}

This paper is about the role the student knower ${ }^{1}$ plays in enabling access in the sciences. Science higher education students in South Africa, where this study is located, are performing particularly poorly in terms of retention and throughput rates. According to a study done on the 2006 cohort at contact universities for the 3-year BSc degree, only $48 \%$ graduated within 5 years and for the 3-year diploma only $37 \%$ graduated (CHE Report, 2013). When broken down by race $^{2}$ the statistics are of greater concern with $39 \%$ of coloureds, $41 \%$ of Africans, $48 \%$ of Indians, and $60 \%$ of whites graduating with a BSc within 5 years (CHE Report, 2013). While conceding there are many nuances in race-class groupings in South Africa (Cooper, 2015), it can be argued that because of historical and social precedents associated with the system of apartheid, African higher education students are mainly from workingclass backgrounds and whites from middle-class ones. Similar class- or race-based disparities

Who a person is and how s/he knows (Maton, 2014).

Race-related terminology is in keeping with the CHE Report (2013): African (black), Indian, coloured (mixed descent), and white. 
in performance in science occur in a global context (see review article by Banerjee, 2016) suggesting that creative and innovative pedagogic transformations are needed to enable access and success for all participating groups in the field.

A common understanding is that science is about neutral and known so-called facts about the natural world, and that we come to know these facts through disinterested and objective inquiry, which means that a priori personal biases, values, or emotions do not form part of the inquiry (McComas, 2002). This empiricist view of science is often translated into a pedagogy in which the primary focus is on the transmission of decontextualised disembodied knowledge and, since learning is assumed to be an individualised cognitive process (Leach \& Scott, 2003), responsibility for knowledge acquisition often rests with the learner. For this reason, content-laden, overloaded curricula are common, particularly in university contexts, despite there being much evidence to suggest that they can be inadequate in promoting student learning (see Case, 2013; Leach \& Scott, 2003; Ramsden, 2003).

Underpinned by a realist ontology that recognises the reality of the natural world beyond our experiences and beliefs (Matthews, 2015), this paper draws on a constructivist epistemology that views scientific development and inquiry as being inherently social in nature (see Carter, 2007). Stemming from this, it also views science learning as a social process, influenced by underpinning norms and values, requiring curricula and pedagogic practices that take this into account. In this regard it employs the conceptual and analytical tools developed by sociologists of education Bernstein (2000) and Maton (2014) to address the question of how and why student knower attributes (disposition/s, value/s, and gaze/s) are valued or legitimated in a higher education science foundation course. Rather than serving as an evaluation of the curriculum per se, the data is instead used to develop more generalised conceptual thinking about the role of knower attributes in access in the sciences.

\section{Conceptual and analytical framework: Legitimation Code Theory}

Both Bernstein (2000) and Maton (2014) have developed fine-grained theoretical and analytical tools that enable the close-up study of curriculum, pedagogic, and assessment practices. Central to their work are the concepts of codes and legitimation. Codes are the organising principles or rules of the game, or a practice. By engaging in a practice in a particular way an actor is making a claim for legitimacy of the practice as well as for the underpinning code/s (Maton, 2014). However, because these codes or rules are often implicit they can serve to exclude. By analysing educational practices using Legitimation Code Theory (LCT) underpinning codes can be surfaced, which allows for their effects to be considered (Maton, 2014).

Two key LCT codes, knowledge and knower codes, are based on the principle that "practices and beliefs are about or oriented towards something and by someone"3 (Maton, 2014, p. 29,

In LCT terms referred to as the Specialisation dimension of a practice (Maton, 2014). 
emphasis added). This allows for analytical distinction between two sets of relationsepistemic and social. Epistemic relations relate to "what can be legitimately described as knowledge" and social relations relate to "who can claim to be a legitimate knower" (p. 29). These two relations therefore indicate "what counts" (Luckett \& Hunma, 2014, p. 183) in a particular practice. The basis for legitimacy in many disciplines in the humanities does not depend on acquisition of specialised knowledge but, rather, on the attributes of the knower. These disciplines are therefore considered to represent knower codes. In contrast, the basis for legitimacy in the field of science and in science disciplines depends on possession of specialised knowledge rather than on the attributes of the knowers. Sciences and associated disciplines are therefore considered to represent knowledge codes. This paper considers the role a knower code may play in students' accessing of the sciences.

For Maton (2014) knowers can be distinguished based on who knowers are (kinds of knowers) and how they know (ways of knowing). When a practice bases legitimacy on how someone knows, it requires a knower to see and do things in particular ways and involves acquiring a feel for the practice through prolonged participation and apprenticeship. These knowers are said to have a cultivated gaze, where a gaze refers to a particular mode of recognising and realising what counts or is valued in a certain context (Bernstein, 2000). In contrast, when legitimacy in a practice is premised on who someone is, the kind of knower is important and legitimacy stems from their social position (such as in standpoint theory based on race, class, or gender), and they are said to be in possession of a social gaze. Practices requiring both a particular kind of knower based on their social position as well as a particular way of knowing based on apprenticeship by an expert knower, legitimate a born gaze. Practices that require neither a specialised knower nor a specialised way of knowing are said to require knowers with a trained gaze that can be gained through explicit teaching in specialised skills and procedures.

Humanities disciplines would usually legitimise one of a cultivated, social, or born gaze. In contrast, science disciplines are considered to legitimise a trained gaze. Since becoming a knower in the sciences is considered a matter of training, Maton (2014) suggests that anyone, regardless of their social background, can be successful in science provided they can develop the knowledge, skills, and appropriate trained gaze. This raises the question as to why students in South Africa and elsewhere, and certain groups of students in particular, are often so unsuccessful in science. This study provides some insight into this issue by examining the kinds of knowers who are being legitimated in the curriculum of a higher education science foundation course. It forms part of a larger study that examines the role both knowledge and knower codes play in enabling epistemological access in the sciences (Ellery, 2016).

\section{Context of the study}

The main government-funded means of addressing equity and access issues in South Africa is through Extended Curricula Programmes (ECPs) in which students who do not meet the direct-entry faculty requirements take an additional year to achieve their degree. For most students in ECPs, neither their home backgrounds (Dukhan, Cameron, \& Brenner, 2011) nor 
school contexts (CHE Report, 2013; Fiske \& Ladd, 2004) have prepared them well for success in tertiary institutions. Based on a range of entry criteria, students in the Rhodes University (RU) Science ECP are mainly African, working-class, first-generation higher education learners who attended poor quality and under-resourced schools generally, and for whom English is an additional language.

A single, year-long, multidisciplinary foundation course called Introduction to Science Concepts and Methods (ISCM) is the main course in the RU Science ECP and is the focus of this paper. The aims of ISCM are (a) to teach the concepts, literacies, and academic practices required by first-year students in a science degree, and (b) to prepare students for success in mainstream (SESP Review Report, 2011). Four mainstream staff from physics, chemistry, earth sciences, and life sciences disciplines provide disciplinary input in lectures and practicals, and two literacies facilitators, one with a science background (the author) and one with a language and literacies background, provide much additional support in tutorial sessions. The literacies work, which is deeply embedded in the disciplinary contexts, focuses on broad scientific concepts (for example, hierarchies, spatial and temporal scales, diversity, valuing of empirical data), how scientific knowledge is constructed (different kinds of reasoning, observation, measurement, experimentation), the basis upon which claims are made, and reading, writing, and thinking critically in the sciences. Both literacies and disciplinary staff work closely as a team to provide a carefully coordinated and structured curriculum for the 50 students.

\section{Methodology}

Data for this study was derived from a number of sources over a period of a single teaching year. First, semi-structured interviews, with questions relating mainly to the perceived purpose of the course, were conducted with five of the six teaching staff. Second, document analysis of the course outline and handouts for lectures, practicals, and tutorials provided an indication of the purpose and objectives of the course as articulated to students, as well as of the course content, skills, attitudes, and behaviours expected of students. Furthermore, document analysis of student critical reflections relating to their own progress, attitudes, and approaches to their studies throughout the year provided insights on personal development and how students were engaging with their studies. To support my own teaching as the scientific literacies facilitator, I attend most teaching sessions of other staff members during which I make informal observations related to class activities constantly. These observations gave rise to the third data source and provided insights on how knower attributes are legitimated and valued in ISCM pedagogic interactions. The fourth data source, which also revealed legitimation of knower attributes, came from critical reflections of my own pedagogic interactions as recorded in a reflections journal.

To bridge the discursive gap between the abstract theoretical concepts of knowers and their gazes and the empirical data from interviews, document analysis, observations, and reflections, an "external language of description" (Bernstein, 2000, p. 133) was developed. This entailed repeated analytical movement between abstract concepts and concrete data, 
ultimately resulting in categorisation of two kinds of knowers who are being legitimated in ISCM: a learning-context knower (or science learner) and a production-context ${ }^{4}$ knower (or scientist). I draw on this data to describe these in turn in the following sections.

Although being an insider researcher provided ease of access to data and legitimacy with participants, I was highly conscious of the need to be critically reflexive of a context with which I was familiar, and which had become what Chavez (2008) would describe as normalised. Furthermore, to establish internal validity (or credibility) and reliability (or dependability) I used member checking with all participants as well as triangulation in terms of data sources and methods, as suggested by practitioners of qualitative research (Creswell, 2007; Maxwell, 2012).

\section{Learning-context knowers: Becoming and being science learners}

When they were asked about the purpose of ISCM it was clear from interviews that staff members perceived the primary goal of ISCM as enabling students to become effective science learners in an academic context. Staff members articulated the norms, values, and practices they perceived as necessary for becoming a science learner in a number of ways. First, they mentioned the need for students to learn how to study and their comments quite often related to metacognitive aspects of thinking about learning. As one mentioned,

... they need to know what to do if they don't understand . . thinking about how they learn and what they're going to learn and what they're going to do about it ... and I suppose also realising that they don't know what's going on ... a lot of it is, you know, helping them know how to study and thinking about study ... to learn that there are places that they can go to find answers. (Staff interview, L2)

Four of the five interviewees spoke about appropriate study techniques. As one stated,

... they need to become capable as students to study effectively ... unlearning of poor learning techniques... (Staff interview, L5)

All staff members commented on the need to learn to work independently. One lecturer added that this required reflexivity.

Students need to work independently, not always rely on someone to teach them everything nor rely on someone to always check whether they have understood ... requires reflexivity ... (Staff interview, L1)

The terms are derived from Maton's (2014) epistemic-pedagogic device where production-context relates to the field of production where new knowledge is produced, and the learning-context relates to the field of reproduction where learning takes place. 
All staff members spoke about students needing to develop good conceptual understanding rather than merely rote learning and needing to engage at a higher level. In this regard, one staff member said that students need to

... develop an ability to understand and to ask the right questions of what's in front of them . . . to bring them up to the right kind of academic level in terms of the scientific reasoning approach and that fact that they can't rote learn ... (Staff interview, L3)

Similarly, another maintained that students need to

... have the skills to select the right kind of material, to extract the meaning, to put it together into coherent text and this way to generate a new piece of knowledge . . . be able to engage with course handouts and material on a higher level ... acquisition of higher-level learning techniques ... (Staff interview, L5)

Two staff members recognised the important role that affect plays in student learning. The first suggested,

I've always felt that the work that [we] do is very much around the person, and a lot less around the science. It's about motivation and self-esteem but always within the context of becoming a scientist, and thinking and being curious ... it's all those more socio-affective things than necessarily the science. (Staff interview, L1)

The second said,

... [the course] starts off as not so difficult and it gets more challenging where they are definitely going to find things that they don't know ... you are building their confidence in the transition. (Staff interview, L2)

When questioned about successful learners in their own disciplines, the disciplinary staff members seldom mentioned particular disciplinary content knowledge and practices but spoke, instead, of knower dispositions such as willingness to engage, participate, be challenged, and seek help as well as being confident, motivated, curious, and reflective.

The aims of the course, as articulated in the above statements, point to a recognition of the need to develop knower attributes that are appropriate for learning in a higher education science context. This includes dispositions such as being independent, engaged, critical, reflective, confident, and responsible for one's own learning, all of which I encapsulate here as being autonomous learners. Bhattacharya and Chauhan state that autonomy is defined by a "capacity for detachment, critical reflection, decision making, and independent action" (2010, p. 376). An autonomous learner should take responsibility for their own learning, be able to set goals and find ways of meeting those goals by choosing appropriate strategies and by monitoring and evaluating progress, and responding appropriately (Bhattacharya \& Chauhan, 2010; Po-Ying, 2007). 
The above interview data relates to perceived pedagogy and the needs of students as expressed in staff interviews. However, course documents, pedagogic interaction observations, and my own and student critical reflections relate to the enacted pedagogy and provide an indication of how ISCM pedagogy enables the development of autonomous learners. The data indicates that explicit articulation of expectations as well as modelling and scaffolding of practices are common.

In this regard all staff members are deliberately overt about expectations with respect to students being active, engaged, and independent self-regulated science learners. However, the two literacies practitioners actively support students in this regard. For example, in tutorial sessions that relate to their developing independent learning practices, pedagogic observations and my own critical reflections indicate that students are explicitly informed that these activities are modelling practices expected of them in the future without lecturer input. Course documents reveal that such tutorials cover developing good note-taking and notemaking practices, consolidating lectures, doing what we call joining the dots, developing a big picture, linking theory with practice, testing understanding, asking questions, practising technical aspects (such as calculations, measuring, estimating), responding to feedback, and locating and using resources (past papers, readings, resource notes, handouts, dictionaries, internet, YouTube, and model answers).

Pedagogic observations and my own critical reflections reveal a deliberate scaffolded reduction of support by the literacies lecturers. For example, preparation for and consolidation of lectures is a key tutorial activity during term one, but this decreases during term two and desists by term three. However, students are constantly reminded that this support is being deliberately withdrawn so that they may continue the work independently. Similarly, individualised feedback from staff on drafts of large assignments is gradually withdrawn, being replaced by supported peer-evaluation of assignments in the third term and supported self-evaluation in the fourth term. The reasons for these shifts in terms of developing learner autonomy are discussed with students. Self-reflective exercises in the literacies tutorials also contribute in this regard. One student indicated an appreciation that they need to develop understanding at university themselves

... because the lecturer is not like teaching you the school work where they tell you each and every detail but they give you the key notes then you have to go back to the library, or wherever you get the information and try to think what it's trying to tell you ... I think the lecturers are highlighting what you must [know], and everything that is said there is important, then you have to follow it ... I know that after the lecture I have to go and do the work again. (Student critical reflection, S14)

In addition, course documents and pedagogic observations indicate that independent work is an underpinning aspect of a research project in the second semester during which students examine the influence of an environmental factor on the growth of plants in pots. Although given guidance on proposal writing, data collection and analysis, and final poster and oral presentation, students are expected to drive the entire process themselves. As one student stated in a critical reflection on working independently, 
During my research project I have encountered numerous challenges which I think were caused by the fact that I had to adapt myself to the fact that I was independent and had only my partner to rely on ... . included the fact that I had to take care of the environment my research treatments were under . . . being responsible for the recording of data which was very important and the core underlying factor of our experiment ... (Student critical reflection, S22)

The above analysis suggests that all ISCM staff have interpreted the second aim of preparing students for success in mainstream in a relatively broad sense through focusing on social relations that enable the development of autonomous learners in the sciences. This is embedded in the notion that ISCM is a foundation course that provides much support to students in their first year at university, but that students will need to work in autonomous and independent ways once in mainstream, where opportunities for support are greatly diminished. One staff member encapsulated these ideas thus:

When they leave us [to go into mainstream] students need to be able to get on with the job. They need to be able to work on their own, find help when they need it . . know when they are battling and know what to do about it. (Staff interview, L1)

In developing the course, ISCM staff have therefore identified that learning in an academic context, particularly in the sciences, requires knower dispositions, values and attributes such as being engaged, critical, reflective, confident, independent, proactive, responsible, and autonomous-aspects that are being overtly articulated as well as modelled in tutorials.

\section{Production-context knowers: Becoming and being scientists}

In contrast to the learning-context knower the production-context knower is based on a valuing of epistemic norms and values that underpin the process of students becoming and being scientists. Science is a way of knowing and attempts to generate reliable knowledge about the natural world (Matthews, 2015). The practices that promote this goal relate mainly to how knowledge is generated (e.g., inductively through seeking patterns, or deductively through hypothesis generation and controlled experiments, careful observation and measurement, making and confirming predictions) and to the basis on which claims are made (e.g., based on empirical evidence, recognising the changing and therefore tentative nature of science). Therefore, for students to become and be scientists they would be expected to develop practices and knower dispositions based on scientific epistemic values linked to knowledge generation and claim-making, such as being rigorous, curious, reliable, and objective, working accurately and precisely, estimating appropriately, observing carefully, seeking simple solutions, and thinking analytically and critically.

This type of work on epistemic values frames much of the work done in ISCM and is usually addressed in the context of understanding the nature of science. As one staff member stated, "Wherever appropriate both the understanding of the concept, as well as the valuing of the concept, are considered" (Staff interview, L1). I present here only three examples from among many in ISCM. First, when writing a scientific laboratory report on the effect of 
weight training on muscle strength, students need to know that scientists in this context cannot prove something to be true but they can add evidence to support an idea or hypothesis. Consequently, their writing would need to reflect both the tentative and fallible nature of science. Second, when, for example, plants die unexpectedly in the previously-mentioned independent research project, this presents an opportunity to discuss not only scientific concepts related to replicates and statistical analysis in experimental design, but also knower attributes such as being objective, trusting the empirical data, reporting honestly, and thinking critically and creatively to explain unexpected phenomena. Third, when students are taught to measure precisely and accurately in physics and chemistry practicals or observe meticulously rock features on a geology field trip, the value of and necessity for such careful working in the development of new science knowledge is discussed with them.

\section{Discussion: Knower attributes in science}

The analysis indicates that two kinds of knowers are legitimated in the ISCM curriculum-a learning-context knower, in this case a science learner, and a production-context knower, or scientist. Each knower is intimately shaped by the other. In other words, the productioncontext knower who is engendered needs to be a certain kind of learner to access the sciences, and the learning-context knower who is being legitimated is not necessarily a generic knower who would be successful in any higher education context. In this regard, I would argue that when ISCM tries to engender autonomous and independent learners, where students need to be organised, purposeful, and systematic in their learning practices and develop a deep questioning approach related to their own conceptual understanding, this is better suited to disciplines in the sciences than, for example, the dramatic arts, where perhaps a creative, expressive, networked, and visually-communicative approach to being an autonomous learner may be more appropriate.

As mentioned above, every knower has a gaze. By indicating that both learning-context and production-context knowers are valued in ISCM pedagogic practices, I am making a claim for something more than a trained gaze. In both cases I suggest a gaze in which the knower's way of knowing is valued (i.e., a cultivated gaze) rather than a gaze in which the kind of knower is valued (i.e., a social gaze).

This claim for two forms of cultivated gaze is strengthened by the ideological contention that all practices have socio-cultural origins and that accessing them, and therefore developing the appropriate gaze, is neither a neutral nor an uncontested process (Bernstein, 2000). This suggestion is based on four interlinked premises. First, any social practice is underpinned by norms, values, attitudes, motivations, and perspectives. Second, taking on new norms, values and attitudes is a social act that results in developing new knower attributes. Third, becoming a new kind of knower is difficult identity work that takes time and effort. Fourth, the greater the gap between prior knower attributes and those expected in the new context, the more time it will take, and the more guidance, immersion, and socialisation in the new context is required. Given these four premises it is, in fact, difficult to envisage any form of trained gaze. 
The idea of prolonged participation in, and apprenticeship into, the new context is key in developing a cultivated gaze (Maton, 2104). This is best illustrated by my looking at the two knower types identified in this study in turn, and in so doing drawing on the distinction of acquisition through apprenticeship and learning or training (Maton, 2014) through direct instruction, a distinction made by others as well (see Gee, 2012; Morrow, 2007).

In terms of enabling a learning-context knower, I make the argument that, since learning science in academia requires acquisition of knower attributes based on norms and values of the specific context, they cannot simply be taught in neutral and acontextual ways but must be embedded in context. For example, science academia requires learners to be responsible for their own knowledge and, therefore, to work in self-regulated ways to develop real, rather than rote, understanding. If a learner comes from a home or social context in which communal and negotiated interactions are more valued than independent ways of working, as do many students in foundation courses in South Africa (Dison, 1997; Ellery, 2016; Niven, 2005), or, if their educational context has resulted in an underdeveloped capacity for independent reading (Mgqwashu, 2012), autonomous learner dispositions and practices will be foreign to them and will therefore be more difficult to take on. Although explicit instruction would assist, apprenticing through modelling, scaffolding, and supported interaction by experienced others would facilitate the becoming and being of such an autonomous learner. In another example, learning to know whether one understands a difficult concept (i.e., cultivating a metacognitive understanding of the nature of understanding in academia) cannot simply be taught through direct instruction; it is about honing appropriate reflective and questioning practices and developing metacognitive awareness within the context of a particular discipline. As Bhattacharya and Chauhan state, autonomy does not happen on its own: it requires "[i]nteraction, negotiation, [and] collaboration" (2010, p. 377).

In terms of enabling a production-context knower (or scientist), I make the same argument. Since the values and associated norms and practices of science have developed in particular social contexts, they, too, cannot simply be addressed acontextually. For example, being objective is highly valued in science. However, this is not a natural way of working or thinking for most of us since we tend to draw automatically on our experiences and feelings to make judgments about, and develop understanding of, the world around us. I contend that suppressing our subjective perspective is not simply a matter of training but, rather, requires socialisation into practices that not only require the learning of technical practices to gather objective empirical data, but also require the development of attitudes and dispositions that allow us to value such data and give us the confidence to believe in what the data is telling us. As Matthews (2015) states, much of western science does not make intuitive sense and therefore requires apprenticeship into scientific traditions.

This argument runs somewhat counter to Maton's (2014) claim that in the sciences legitimacy arises from the knowledge one possesses rather than from any sort of privileged (cultivated, social, or born) gaze. While knowledge is clearly highly valued in science, I suggest here that the gaze in science, although not necessarily dominant, may in fact be a 
privileged gaze. Maton (2014) claims that the sciences engender a trained gaze that is gained through "training in specialised principles or procedures" (p. 95) and "in principle anyone can be trained into the legitimate gaze" (p. 96). I think this may well be true for many middleclass learners who enter higher education as the right kind of knower with the right kind of gaze for orthodox, western sciences. In other words, their home and educational backgrounds have engendered the necessary privileged gaze such as being objective, analytical, and critical. However, it is unlikely that mere training of a student entering higher education with a subjective, non-analytical, and uncritical gaze would result in their easily developing the required gaze but would require, rather, social processes of active participation and enculturation.

I suggest that the concept of a trained gaze in the sciences may have developed because science practices have become so normalised in western, middle-class society that, for the majority of science academics, the socio-cultural nature of science and its underpinning values are tacit and even unarticulated (Jacobs, 2007). Science is treated as a disinterested and acontextual set of practices that can be overtly taught. However, in this paper I suggest, as does relatively recent work by Wolff and Hoffman (2014) in engineering, that knower attributes and a privileged (cultivated) knower gaze may be more important in the sciences than previously imagined.

In this regard, the broader work in which this study is located, through its use of Bernstein's (2000) concept of acquisition of recognition and realisation rules, indicates an important aspect of social relations: being both a science knower and a science learner is in fact key to accessing the powerful science knowledge (Ellery, 2016). It, too, develops the idea, as does this study, that prior educational and social experiences play a significant role in attaining this gaze. These ideas can offer an explanation for the disparity in performance between race groups in higher education in South Africa. The combination of home and school cultural conditioning of working-class African students, as well as a strong focus on content knowledge in most science curricula, is likely playing a role in hindering epistemological access for this group of students. Research in a broader context supports the contention that formal curricula are generally better geared towards accommodating middle-class than working-class students (Archer, Hutchings, \& Ross, 2003; Arum, Gamoran, \& Shavit, 2012; Bernstein, 2000).

\section{Concluding comments}

This paper is about social relations and knowers in the sciences and how they may be more important in enabling access than previously realised. In this regard I make two main conceptual contributions. First, two kinds of knowers are identified: learning-context knowers for whom the focus is on affective, moral, and social values of students as learners, and production-context knowers for whom the focus is on epistemic values of the field or discipline. Although both sets of social relations and their associated values are likely present in any educational practice, studies usually focus on either one or the other. Examining them together in this study allows for a more holistic, nuanced, and close-up analysis of a 
foundation educational practice in which both sets of social relations are equally valued. I suggest this dual-focussed framework could prove useful even in non-scientific and nonfoundational contexts to indicate where pedagogic effort is required depending on student needs.

Second, I argue that acquisition of knower attributes appropriate to science and science learning is unlikely to be a matter of mere training, but is, rather, one of cultivation. This argument is based on the social realist assumption that all practices, even scientific ones, are socially and culturally embedded and that becoming and being an active and contributing member of these practices requires some explicit instruction, but, more importantly, immersion and enculturation into the ways of being appropriate to the practice. This appears to be particularly so when cultural conditioning in the working-class home and school environments do not align well with expectations at university, making access for some extremely difficult. This study suggests, as does Case (2013) in her work on access in engineering, that space should be created in current content-laden science curricula to focus, too, on knower attributes. While this represents a weakening of epistemic relations and strengthening of learning-context and production-context social relations, it is not a suggestion to move away from the knowledge code that is central in sciences, but is, rather, a shift in emphasis to better accommodate knower codes, too. Although articulated slightly differently, a similar suggestion is made by Muller (2015) when he speaks of the need for a third curriculum space in science, technology, engineering, and mathematics (STEM) education that lies between a knowledge-dominated traditionalism and skills- and learningdominated progressivism spaces.

The extent to which a curriculum accommodates knower attributes, such as identified in this study, would depend on the purpose of the curriculum and the background context of students. Based on the argument that some groups of students are better prepared for epistemological access and success in science in higher education than others, it is a matter of social justice that curricula today more appropriately accommodate the range and diversity of students entering the sector. In this paper I suggest that social relations and associated knowers, who have traditionally been ignored or downplayed in science, could play a key role in enabling such access. I further suggest that making the codes or rules explicit is an important part of this process.

\section{Acknowledgments}

I thank Professor Chrissie Boughey sincerely for her contribution to this work, as well as an anonymous reviewer who provided valuable comment on this manuscript. The study was supported by funding from the National Research Foundation (Grant no: 92685) and Rhodes University. 


\section{References}

Archer, L., Hutchings, M., \& Ross, A. (2003). Higher education and social class: Issues of exclusion and inclusion. London, UK: RoutledgeFalmer.

Arum, R., Gamoran, A., \& Shavit, Y. (2012). Expanded opportunities for all in global higher education systems. In L. Weis \& N. Dolby (Eds.), Social class and education: Global perspectives (pp. 15-36). New York, NY: Routledge.

Banerjee, P. A. (2016). A systematic review of factors linked to poor academic performance of disadvantaged students in maths and science in schools. Cogent Education, 3, 117. doi:10.1080/2331186X.2016.1178441.

Bernstein, B. (2000). Pedagogy, symbolic control, and identity: Theory, research, critique. Lanham, MD: Rowman \& Littlefield.

Bhattacharya, A., \& Chauhan, K. (2010). Augmenting learner autonomy through blogging. ELT Journal, 64(4), 376-384.

Carter, L. (2007). Sociocultural influences on science education: Innovation for contemporary times. Science Education, 92(1), 165-181.

Case, J.M. (2013). Researching student learning in higher education: A social realist approach. London, UK: Routledge.

Chavez, C. (2008). Conceptualizing from the inside: Advantages, complications, and demands on insider positionality. The Qualitative Report, 13(3), 474-494.

CHE (Council on Higher Education) Report. (2013). A proposal for undergraduate curriculum reform in South Africa: The case for a flexible curriculum structure. Pretoria, South Africa: CHE.

Cooper, D. (2015). Social justice and South African university student enrolment data by 'race', 1998-2012: From 'skewed revolution' to 'stalled revolution.' Higher Education Quarterly, 69(3), 237-262.

Creswell, J.W. (2007). Qualitative inquiry and research design: Choosing among five approaches (2nd ed.). Thousand Oaks, CA: SAGE.

Dison, A. (1997). The acquisition and use of literacies within social contexts: Tsholo Mothibi's story. Academic Development, 3(2), 53-74.

Dukhan, S., Cameron, A., \& Brenner, E. (2011). The influence of differences in social and cultural capital on students' expectations of achievement, on their performance, and on their learning practices in the first year at university. International Journal of Learning, 18(7), 337-351. 
Ellery, K. (2016). Epistemological access in a science foundation course: A social realist perspective (Unpublished doctoral dissertation). Rhodes University, South Africa.

Fiske, E., \& Ladd, H. (2004). Elusive equity: Education reform in post-apartheid South Africa. Cape Town, South Africa: HSRC Press.

Gee, J. P. (2012). Social linguistics and literacies: Ideology in discourse (4th ed.). Abingdon, UK: Routledge.

Jacobs, C. (2007). Towards a critical understanding of the teaching of discipline-specific academic literacies: Making the tacit explicit. Journal of Education, 41, 59-82.

Leach, J., \& Scott, P. (2003). Individual and sociocultural views of learning in science education. Science \& Education, 12(1), 91-113.

Luckett, K., \& Hunma, A. (2014). Making gazes explicit: Facilitating epistemic access in the humanities. Higher Education, 67, 183-198.

Maton, K. (2014). Knowledge and knowers: Towards a realist sociology of education. New York, NY: Routledge.

Matthews, M. (2015). Science teaching: The contribution of History and Philosophy of Science (2nd ed.). New York, NY: Routledge.

Maxwell, J. A. (2012). Qualitative research design: An interactive approach (3rd ed.). London, UK: SAGE.

McComas, W. F. (2002). The principal elements of the nature of science: Dispelling the myths. In W.F. McComas (Ed.), The nature of science in science education: Rationale and strategies (pp. 53-70). New York, NY: Kluwer.

Mgqwashu, E. (2012). On teaching reading for epistemological access. In R. Dhunpath \& R. Vithal (Eds.), Alternative access to higher education: Underprepared students or underprepared institutions? (pp. 238-257). Cape Town, South Africa: Pearson.

Morrow, W. (2007). Learning to teach in South Africa. Pretoria, South Africa: HSRC Press.

Muller, J. (2015). The future of knowledge and skills in science and technology higher education. Higher Education, 70, 409-416.

Niven, P. M. (2005). Exploring first year students' and their lecturers' constructions of what it means to read in a humanities discipline: A conflict of frames? South African Journal of Higher Education, 19(4), 777-789.

Po-Ying, C. (2007). How students react to the power and responsibility of being decisionmakers in their own learning. Language Teaching Research, 11(2), 225-241. 
Ramsden, P. (2003). Learning to teach in higher education. London, UK: Routledge.

SESP (Science Extended Studies Programme) Review Report. (2011). Curriculum Review:

Science Extended Studies Programme, Rhodes University. Internal report, Rhodes University, South Africa.

Wolff, K., \& Hoffman, F. (2014). "Knowledge and knowers" in engineering assessment. Critical Studies in Teaching and Learning, 2(1), 74-95. 